\title{
Mechanical ventilation in patients with SARS-CoV-2 pneumonia
}

\begin{abstract}
The coronavirus $(\mathrm{CoV})$ belongs to a family of viruses that can cause a variety of clinical presentations, including catarrhal symptoms, cough, fever, respiratory distress, and conditions such as pneumonia, among others. Worldwide, more than 29 million confirmed COVID-19 cases have been reported with 926,544 deaths, $51 \%$ of which correspond to the Americas. Careful observations have hypothesized that patients present with different clinical patterns that depend mainly on 3 factors: (1) severity of infection and host response, physiological reserve and comorbidities (2) ventilatory response to hypoxemia and (3) the delay from the onset of symptoms and evaluation in the hospital. About $4.4 \%$ of patients require IMV during the first 14 days after symptoms start and reach a high mortality rate. This disease mainly shows two behaviors related to time: phenotype L, Low elastance [high compliance] and phenotype H, High elastance [low compliance]. The L phenotype, with low V/Q ratio, low lung weight, and low potential for recruitment occurs early in the disease. The $\mathrm{H}$ phenotype is characterized by low compliance, high shunt levels, high lung weight, and high potential for recruitment, and it usually manifests within 7days. In our experience, there would be a third group that progresses to early pulmonary fibrosis characterized by very low compliance, making the ventilatory process exceedingly difficult (they require a low PEEP [6-8cmH2O] and very low VT 4-6ml/kg predicted body weight. These patients retain $\mathrm{CO} 2$ and may require extracorporeal $\mathrm{CO} 2$ removal (ECCO2R). Although SARS CoV-2 pneumonia does not evolve as a classic ARDS, emerging evidence suggests that ARDS associated with CoVID-19 evolves with acute respiratory failure and lung mechanics typical of a historical ARDS. One aspect that could differentiate them is related to the levels of D-Dimer (DD). The subgroup of patients with DD concentrations higher than the median and a static compliance equal to or less than the median (HDLC: High D-dimers, low compliance) have at 28-days mortality higher than the rest of the groups, such as: high DD with high compliance (HDHC), low DD with low compliance (LDLC) and low DD with high compliance (LDHC). The 28-day mortality for HDLC was $56 \%$ and $27 \%$ for LDHC Up to the present time, IMV with open lung approach (OLA) has not been shown to reduce mortality; it has only accomplished to improve oxygenation and reduce driving pressure, without exerting deleterious effects such as barotrauma or increases in mortality.
\end{abstract}

Keywords: coronavirus; ECCO2R, extracorporeal CO2 removal, DD, D-dimer, open lung approach, IMV, invasive mechanical ventilation, PBW, predicted body weight, PRM, pulmonary recruitment maneuvers
Volume 13 Issue 6 - 2020

\author{
Vinko Tomicic, ${ }^{1,2}$ Krasna Tomicic $\mathrm{MS}^{3}$ \\ 'Department of Intensive Care, ICU Director of Antofagasta \\ Region Hospital, Chile \\ 2Department of Surgery, University of Antofagasta, Chile \\ ${ }^{3}$ Medical student of Universidad del Valle, Bolivia
}

Correspondence: Vinko Tomicic, Department of surgery, University of Antofagasta, Chile, Tel +56974771953 ,

Email vtomicic@gmail.com

Received: December 09, 2020 | Published: December 31,

2020
Abbreviations: $\mathrm{CoV}$, coronavirus; ECCO2R, extracorporeal $\mathrm{CO} 2$ removal; DD, D-dimer; OLA, open lung approach; WHO, world health organization; IMV, invasive mechanical ventilation; PBW, predicted body weight; PRM, pulmonary recruitment maneuvers

\section{Mini review}

The coronavirus $(\mathrm{CoV})$ belongs to a family of viruses that can cause a variety of clinical presentations, including catarrhal symptoms, cough, fever, respiratory distress, and conditions such as pneumonia, among others. ${ }^{1,2}$ World Health Organization (WHO) used the new term coronavirus 2019 (CoVID-19) to refer to a coronavirus that affects the lower respiratory tract. ${ }^{3}$ This virus emerges in Wuhan, China, in late 2019.,5 The current reference name for the virus disease is severe acute respiratory syndrome coronavirus 2 (SARS-CoV-2). It is a zoonotic disease with an animal reservoir and evidence of personto-person transmission. ${ }^{6}$

Transmission of this virus occurs mainly through respiratory droplets, which resemble the spread of the flu. With droplet transmission, the virus is released in respiratory secretions when a person with an active infection coughs, sneezes, or speaks, and can infect another person if it comes into direct contact with the mucous membranes. ${ }^{7}$ Infection can also occur if a person touches an infected surface and then touches his eyes, nose, or mouth.

Worldwide, more than 29million confirmed COVID-19 cases have been reported with 926,544 deaths, $51 \%$ of which correspond to the Americas. ${ }^{8}$ The average incubation period is 5.2days, and the first signs include nonspecific flu-like symptoms, with a variable condition of the respiratory tract, which can manifest as tracheobronchitis, bronchiolitis, in some cases reaching a very serious organizing pneumonia that requires invasive mechanical ventilation (IMV). ${ }^{9}$

Some groups based on careful observations have hypothesized that patients present with different clinical patterns that depend mainly on 3 factors: (1) severity of infection and host response, physiological reserve and comorbidities (2) ventilatory response to hypoxemia and (3) the delay from the onset of symptoms and evaluation in the hospital. About $4.4 \%$ of patients require IMV during the first 14 days after symptoms start and reach a high mortality rate $(40 \%){ }^{10,11}$ 
This disease mainly shows two behaviors related to time: phenotype L, Low elastance [high compliance] and phenotype $\mathrm{H}$, High elastance [low compliance]. The L phenotype, with low V/Q ratio, low lung weight, and low potential for recruitment occurs early in the disease. On the other hand, the $\mathrm{H}$ phenotype is characterized by low compliance, high shunt levels, high lung weight, and high potential for recruitment, and it usually manifests within 7 days. ${ }^{12-14}$ In our experience, there would be a third group that progresses to early pulmonary fibrosis characterized by very low compliance, making the ventilatory process exceedingly difficult (they require a low PEEP [6-8 $\mathrm{cmH} 2 \mathrm{O}]$ and very low VT 4-6ml/kg predicted body weight $[\mathrm{PBW}])$. These patients retain $\mathrm{CO} 2$ and may require extracorporeal $\mathrm{CO} 2$ removal (ECCO2R). ${ }^{15,16}$

In our group (52 patients), before considering pronation and after the patients had been sufficiently resuscitated (MAP $>65 \mathrm{mmHg}$, delta pulse pressure [delta $\mathrm{PP}]<10 \%$ or central venous saturation [SvcO2] $>70 \%$ ), they underwent to pulmonary recruitment maneuvers (PRM) in pressure-controlled mode (with $15 \mathrm{cmH} 2 \mathrm{O}$ driving pressure, respiratory frequency of 20 per minute and I: E ratio of 1: 1), with increases in PEEP of 2 in $2 \mathrm{cmH} 2 \mathrm{O}$ until reaching $25 \mathrm{cmH} 2 \mathrm{O}$. If tolerated, the PEEP was raised to $30 \mathrm{cmH} 2 \mathrm{O}$ and said pressure was maintained for 2 to 3 minutes, then it was returned to $25 \mathrm{cmH} 2 \mathrm{O}$, to later descend in steps $(2 \mathrm{cmH} 2 \mathrm{O}$ at a time), until a PEEP level was achieved that would ensure better compliance, ${ }^{17-21}$ If patients did not tolerate the hemodynamic pre-conditioning test, or if increasing PEEP produced an increase in driving pressure (plateau-PEEP), PRM was interrupted. . $^{13,14}$

In our population, the mean tidal volume (VT) at admission was $389.8 \pm 42$, which corresponds to a VT of $5.93 \pm 0.9$ of PBW. $84.6 \%$ started ventilation in volume-controlled mode and $15.4 \%$ in pressurecontrolled mode. The mean dose of norepinephrine required upon admission to the ICU was $0.058 \pm 0.03 \mu \mathrm{g} / \mathrm{kg} /$ minute.

In general, $10 \%$ of patients admitted to the ICU develop ARDS and despite the advances made in lung protection ventilatory strategies, mortality persists between $30 \%$ and $40 \% .^{22,23}$ Although SARS CoV-2 pneumonia does not evolve as a classic ARDS, emerging evidence suggests that ARDS associated with CoVID-19 evolves with acute respiratory failure and lung mechanics typical of a historical ARDS.24,25 One aspect that could differentiate them is related to the levels of D-Dimer (DD). The subgroup of patients with DD concentrations higher than the median and a static compliance equal to or less than the median (HDLC: High D-dimers, low compliance) have at 28-days mortality higher than the rest of the groups, such as: high DD with high compliance (HDHC), low DD with low compliance (LDLC) and low DD with high compliance (LDHC). The 28-day mortality for HDLC was $56 \%$ and $27 \%$ for LDHC. ${ }^{26}$

Ventilated patients in PP represents about half of our ventilated patients (46\%) and are characterized by high severity scores (APACHE II $>14$ points) and by having greater gasometric compromise on admission than those who remained in supine position (SP). Of the patients who were pronated, $90 \%$ responded to the maneuver showing an increase in $\mathrm{PaO} 2 / \mathrm{FiO} 2$ of $53.5 \pm 3.7 \mathrm{~mm} \mathrm{Hg}$ and a progressive gasometric improvement until day 7 , however, this was not reflected in mortality, this group comprising $75 \%$ of total hospital deaths $(12 / 16)$. The response to the prone position reported in the literature is $70 \% .{ }^{27}$

We evaluated thoracic-pulmonary mechanics and be able to identify those patients who are described as L phenotype (in our group, compliance $>37 \mathrm{ml} / \mathrm{cmH} 2 \mathrm{O}$ ) and those who showed $\mathrm{H}$ phenotype $(<37 \mathrm{ml} / \mathrm{cmH} 2 \mathrm{O})$, however, the clinical behavior does not coincide with what has been described.14 In our series, both phenotypes required similar levels of PEEP $(\sim 12 \mathrm{cmH} 2 \mathrm{O})$ and the increase in $\mathrm{PaO} 2 / \mathrm{FiO} 2$ between admission and the first day of IMV was not statistically different: in phenotype $\mathrm{L}$ there was an increase in $\mathrm{PaO} 2 / \mathrm{FiO} 2$ from $137.3 \pm 36.4$ to $195.4 \pm 67.6(58.1 \pm 31.1 \mathrm{mmHg})$ and in phenotype $\mathrm{H}$ from $138.7 \pm 40.6$ to $194.4 \pm 66.3(55.7 \pm 25.7 \mathrm{mmHg})$ $\mathrm{p}=\mathrm{NS}$. We can say that in phenotype H 15 of 26 patients $(58 \%)$ were pronated and only $9 / 26(34 \%)$ in phenotype $\mathrm{L}, \mathrm{p}=\mathrm{NS}$.

It should be noted that the attending physicians identified the phenotypes by trying to maintain the driving pressure at non-harmful levels for the lung tissue $(<15 \mathrm{cmH} 2 \mathrm{O})$, setting lower VT in the $\mathrm{H}$ phenotype $(374.6 \pm 43.4 \mathrm{ml})$ than in phenotype L $(405.4 \pm 34.6 \mathrm{ml})$, $\mathrm{p}=0.00002 .^{14,26}$

The total number of patients who had to undergo PP had an admission $\mathrm{PaO} 2 / \mathrm{FiO} 2$ of $125.2 \pm 35.8 \mathrm{mmHg}$. Once in the prone position, the mean PEEP was $13.6 \pm 4.6$ and at 72 hours it was $15.1 \pm 4.9$ $\mathrm{cmH} 2 \mathrm{O} .{ }^{14}$ This could be attributed to the fact that the attending physicians, considering of low $\mathrm{PaO} 2 / \mathrm{FiO} 2$, applied higher levels of PEEP. In consequence, compliance alone was not a determining factor in the expected gasometrical response, and $\mathrm{PaO} 2 / \mathrm{FiO} 2$ continues to be the best predictor of severity in these patients. It must be considered that in these patients the pre-PP PEEP was already programmed above $10 \mathrm{cmH} 2 \mathrm{O}^{27}$ Prone Position itself is a recruitment maneuver and probably less harmful than using high airway pressures to overcome the critical opening pressures of the postero-basal territories of the lung. ${ }^{28}$

Up to the present time, IMV with open lung approach (OLA) has not been shown to reduce mortality, it has only accomplished to improve oxygenation and reduce driving pressure, without exerting deleterious effects such as barotrauma or increases in mortality. ${ }^{29}$ Other randomized studies with non-physiological adjustments of PEEP levels (LOVS, EXPRESS, ALVEOLI), have shown to reduce the days of stay in IMV, the duration of organic dysfunctions and the need for extraordinary ventilatory support therapies, effects that were not observed in our patients. ${ }^{30-32}$

Our analysis shows that the characteristics of our patients requiring IMV for SARS-Co-2 pneumonia are different from patients admitted for other causes. The APACHE II is not higher than that previously reported in our country for ARDS of different causes. ${ }^{24}$ However, respiratory failure is severe (mean alveolus arterial oxygen difference at admission of $271 \pm 100$ ) and occupies an important place in the distribution of severity scores, demonstrating that respiratory failure is the main cause of admission of these patients.

These patients were admitted with $\mathrm{PaO} 2 / \mathrm{FiO} 2$ of $138.0 \pm 38.2$ with PEEP $\geq 5 \mathrm{cmH} 2 \mathrm{O}$, constituting a severe ARDS from admission $(\mathrm{PaO} 2 / \mathrm{FiO} 2<150 \mathrm{mmHg})$ and the hospital mortality was $30,8 \%$. In addition, a significant percentage behave with refractory hypoxemia that requires early PP. Considering that a significant percentage of patients who adopted prone position respond to the maneuver, ${ }^{33}$ this improvement does not guarantee a good hospital outcome in SARSCoV-2 pneumonia.

\section{Conclusions}

To program invasive ventilation in patients with SARS CoV-2 pneumonia, we have to identify the patient's phenotype (H or L). Each phenotype has a different potential for recruitment and therefore has a different response to PEEP. It must be taken into account that some patients evolve early with pulmonary fibrosis and low compliance, 
making the ventilation process very difficult. If we associate the levels of DD (D dimer) with the compliance of the respiratory system we can improve the ability to predict mortality at 28days.

\section{Acknowledgments}

None.

\section{Conflicts of interest}

The authors declare there are no conflicts of interest related to the article.

\section{Funding}

None.

\section{References}

1. Huang C, Wang Y, Li X, et al. Clinical features of patients infected with 2019 novel coronavirus in Wuhan, China. Lancet. 2020;395(10223):497506.

2. Chen N, Zhou M, Dong $X$, et al. Etiological and clinical characteristics of 99 cases of 2019 novel coronavirus pneumonia in Wuhan, China: a descriptive study. The Lancet. 2020;395(10223):507-513.

3. https://www.who.int/dg/speeches/detail/who-director-general-sremarks-at-the-media-briefing-on-2019-ncov-on-11-february-2020

4. Zhu N, Zhang D, Wang W, et al. A novel coronavirus from patients with pneumonia in China, 2019. N Engl J Med. 2020;382(8):727-733.

5. Corman VM, Landt O, Kaiser M, et al. Detection of 2019 novel coronavirus (2019-nCoV) by real-time RT-PCR. Euro Surveill. 2020;25(3):2000045.

6. Phan LT, Nguyen TV, Luong QC, et al. Importation and human-tohuman transmission of a novel coronavirus in Vietnam. $N$ Engl J Med. 2020;382(9):872-874.

7. Gaunt ER, Hardie A, Claas ECJ, et al. Epidemiology and Clinical Presentations of the Four Human Corona viruses 229E, HKU1, NL63, and OC43 Detected over 3 Years Using a Novel Multiplex Real-Time PCR Method. J Clin Microbiol. 2010;48(8):2940-2947.

8. https://www.paho.org/es/file/73306/download?token=AMtVXDit

9. Li Q, Guan X, Wu P, et al. Early transmission dynamics in wuhan, china, of novel coronavirus-infected pneumonia. $N$ Engl $\mathrm{J}$ Med. 2020;382(13):1199-1207.

10. Chen N, Zhou M, Dong X, Qu J, Gong F, Han Y, et al (2020) Epidemiological and clinical characteristics of 99 cases of 2019 novel coronavirus pneumonia in Wuhan, China: a descriptive study. Lancet 395(10223):507-513. https://doi. org/10.1016/S0140-6736(20)30211-7.

11. Argenziano MG, Samuel L Bruce ML, Slater CL, et al. Characterization and clinical course of 1000 patients with Coronavirus disease 2019 in New York: retrospective case series. BMJ. 2020;369:m1996.

12. Tsolaki V, Siempos I, Magira E, et al. PEEP levels in COVID-19 pneumoni. Critical Care. 2020;24:303.

13. Gattinoni L, Maissner K, Marini J. The baby lung in the COVID-19. Intensive Care Med. 2020;46(7):1438-1440.

14. Gattinoni L, Chiumello D, Caironi P, et al. COVID-19 pneumonia: different respiratory treatments for different phenotypes? Intensive Care Med. 2020;46(6):1099-1102.

15. Tomicic V, Montalvan C, Espinoza M, et al. Non-Pump extracorporeal pulmonary care: an alternative in the treatment of persistent acute respiratory distress syndrome Pumpless extracorporeal pulmonary care: an alternative in the treatment of persistent acute respiratory distress syndrome. Intensive Medicine. 2008;32(5):253-257.
16. Tomicic V, San Román E, Fuentealba A, et al. Extracorporeal life support in adults with refractory acute respiratory failure. Med Crit. 2017;31(4):224-229.

17. Monge MI, Gil A, Gracia M. Cambios respiratorios y hemodinámicos durante una maniobra de reclutamiento pulmonar mediante incrementos y decrementos progresivos de PEEP. Medicina Intensiva. 2012;36(2):7788 .

18. Tusman G, Bohm SH, Suarez-Sipmann F. Alveolar recruitment during mechanical ventilation. Where are we in 2013? Trends in Anesthesia and Critical Care. 2013;3(5):238-245.

19. Borges JB, Okamoto VN, Matos GF, et al. Reversibility of lung collapse and hypoxemia in early acute respiratory distress syndrome. Am J Respir Crit Care Med. 2006;174(3):268-278.

20. Suarez-Sipmann F, Bohm SH, Tusman G, et al. Use of dynamic compliance for open lung positive end-expiratory pressure titration in an experimental study. Crit Care Med. 2007;35(1):214-221.

21. Tomicic V, Fuentealba A, Martínez E, et al. Fundamentals of mechanical ventilation in acute respiratory distress syndrome The basics on mechanical ventilation support in acute respiratory distress syndrome. Intensive Medicine. 2010;34(6):418-427.

22. Duan EH, Adhikari NK, D'Aragon F, et al. Management of Acute Respiratory Distress Syndrome and Refractory Hypoxemia. A Multicenter Observational Study. Ann Am Thorac Soc. 2017;14(12):1818-1826.

23. Matthay MA, Zemans RL, Zimmerman GA, et al. Acute respiratory distress syndrome. Nat Rev Dis Primers. 2019;5(1):18.

24. Tomicic V, Espinoza M, Andresen M, et al. Characteristics and factors associated with mortality in patients receiving mechanical ventilation: first Chilean multicenter study. Rev Med Chil. 2008;136(8):959-967.

25. Acute Respiratory Distrés Syndrome Part I and Part II, in Cardiopulmonary Intensive Medicine. Vinko Tomicic, Editor. Carolina Campillay, Mediterranean, Santiago de Chile; 2020.

26. Lorraine B Ware. Physiological and biological heterogeneity in COVID-19- associated acute respiratory distress síndrome. Lancet Respir Med. 2020;8(12):1163-1165.

27. Kallet RH. A Comprehensive Review of Prone Position in ARDS. Respir Care. 2015;60(11):1660-1687.

28. Tomicic V, Fidanza L, Espinoza M, et al. Use of a sigmoidal equation to analyze the pressure-volume curve obtained by the low flow method. Crit Care. 2005;9(Suppl 1):P104.

29. Robert M, Kacmarek RM, Villar J, et al. Open Lung Approach for the Acute Respiratory Distress Syndrome: A Pilot, Randomized Controlled Trial. Crit Care Med. 2016;44(1):32-42.

30. Maureen O, Meade MO, Cook DJ, et al Ventilation Strategy Using Low Tidal Volumes, Recruitment Maneuvers, and High Positive EndExpiratory Pressure for Acute Lung Inju.ry and Acute Respiratory Distress Syndrome A Randomized Controlled Trial. JAMA. 2008;299(6):637-645.

31. Mercat A, Richard JC, Vielle B et al. Positive end-expiratory pressure setting in adults with acute lung injury and acute respiratory distress syndrome: a randomized controlled trial. JAMA. 2008;299(6):646-655.

32. Brower RG, Lanken PN, MacIntyre N, et al. Higher versus Lower Positive End-Expiratory Pressures in Patients with the Acute Respiratory Distress Syndrome. N Engl J Med. 2004;351(4):327-336.

33. Guerin C, Reignier J, Richard JC, et al. Prone Positioning in Severe Acute Respiratory Distress Syndrome. NEngl J Med. 2013;368(23):2159-2168. 